

\section{DISCLAIMER}

This report was prepared as an account of work sponsored by an agency of the United States Government. Neither the United States Government nor any agency thereof, nor any of their employees, make any warranty, express or implied, or assumes any legal liability or responsibility for the accuracy, completeness, or usefulness of any information, apparatus, product, or process disclosed, or represents that its use would not infringe privately owned rights. Reference herein to any specific commercial product, process, or service by trade name, trademark, manufacturer, or otherwise does not necessarily constitute or imply its endorsement, recommendation, or favoring by the United States Government or any agency thereof. The views and opinions of authors expressed herein do not necessarily state or reflect those of the United States Government or any agency thereof. 


\section{DISCLAIMER}

Portions of this document may be illegible in electronic image products. Images are produced from the best available original document. 


\section{TABLE OF CONTENTS}

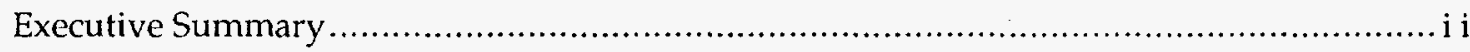

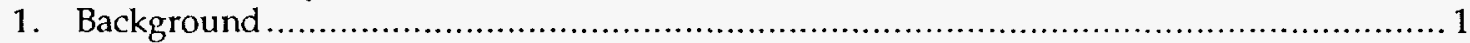

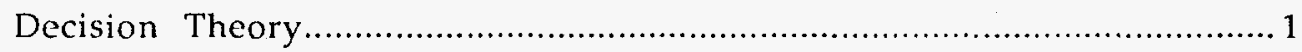

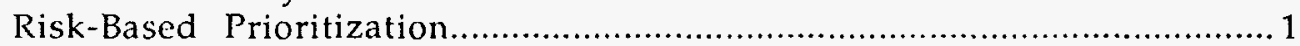

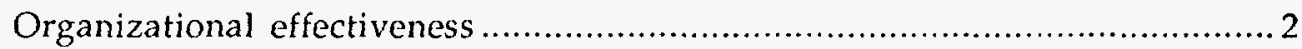

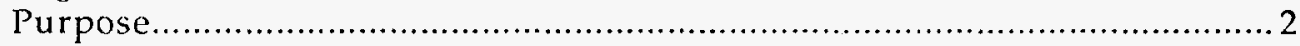

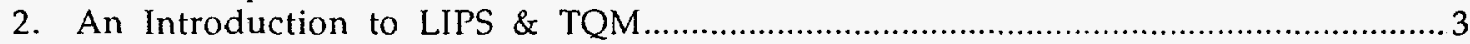

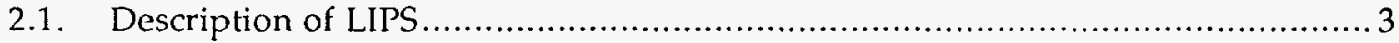

Multiattribute Utility Analysis (MUA) ................................................ 3

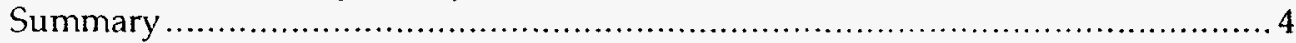

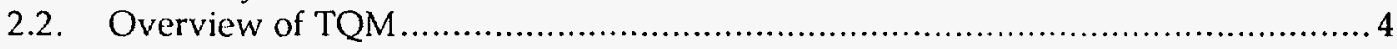

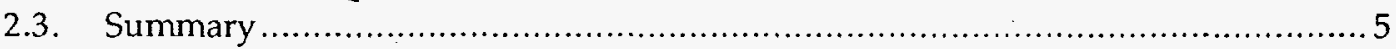

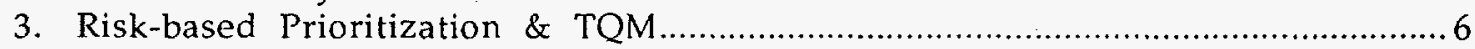

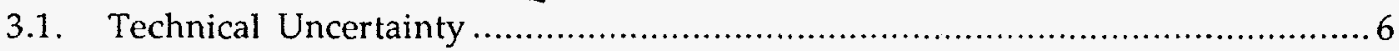

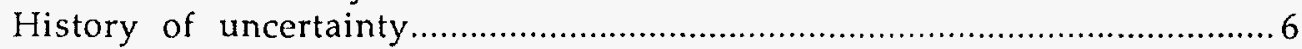

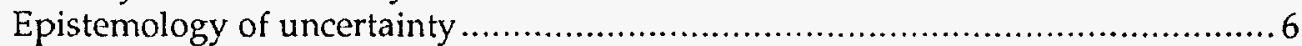

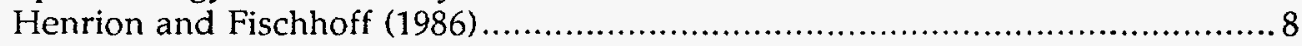

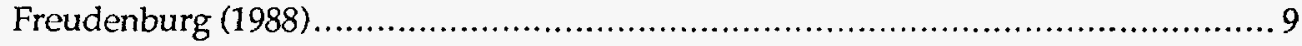

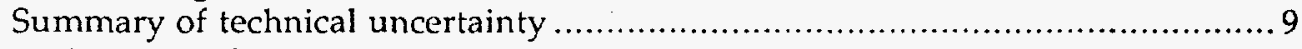

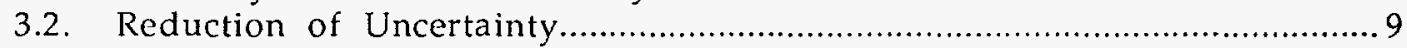

Objective \& quantitative vs. subjective \& qualitative.................................. 9

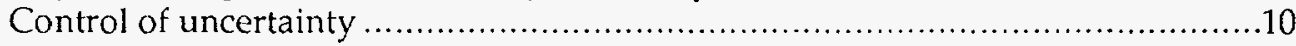

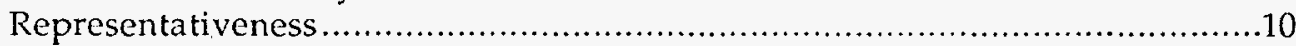

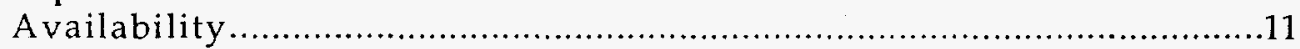

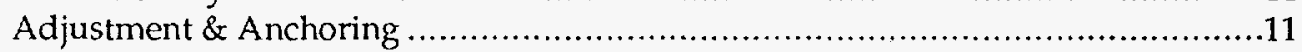

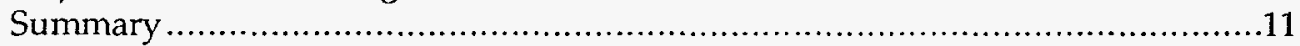

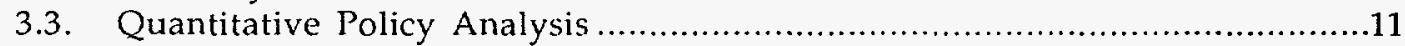

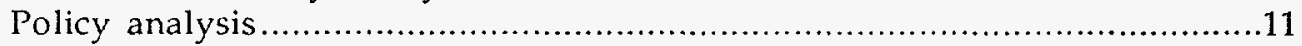

Ethics and quantification of uncertainty .................................................13

3.4. Conduct of Operations, DOE's TQM Program, \& Budget Analysis........................15

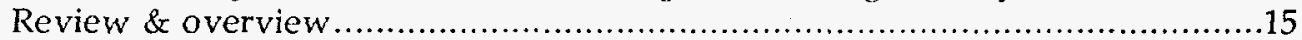

Decision-Theoretic Tools Described in DOE Documents...................................15

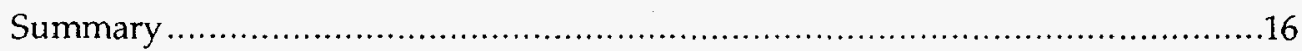

3.5. Integration of TQM, Risk-Based Prioritization, \& Budget Analysis....................16

Ethics of capitalism and TQM ...............................................................16

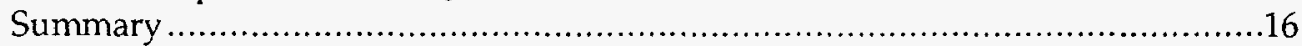

3.6. Use of Measurement in Managing DOE Policy Analysis .............................16

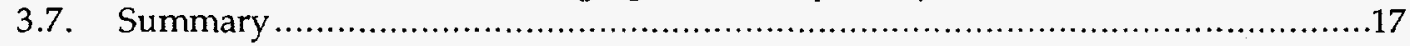

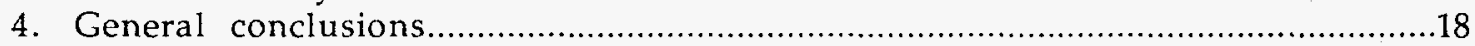

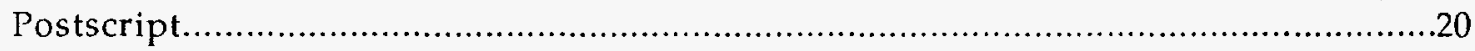

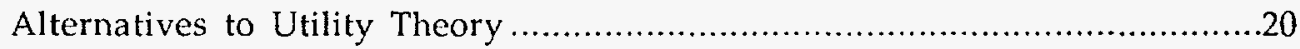

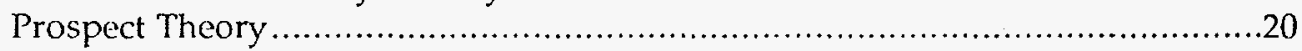

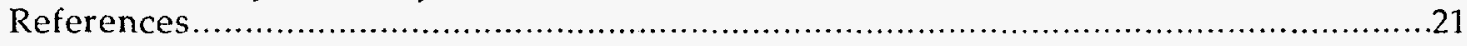

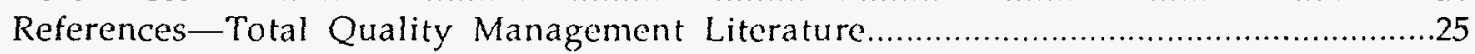




\section{EXECUTIVE SUMMARY}

The climate in which government managers must make decisions grows more complex and uncertain. All stakeholders - the public, industry, and Congress - are demanding greater consciousness, responsibility, and accountability of programs and their budgets. Yet, managerial decisions have become multifaceted, involve greater risk, and operate over much longer time periods. Over the last four or five decades, as policy analysis and decisions became more complex, scientists from psychology, operations research, systems science, and economics have developed a more or less coherent process called decision analysis to aid program management. The process of decision analysis - a systems theoretic approach - provides the backdrop for this paper.

The Laboratory Integrated Prioritization System (LIPS) has been developed as a systems analytic and risk-based prioritization tool to aid the management of the Tri-Labs' (Lawrence Livermore, Los Alamos, and Sandia) operating resources. Preliminary analyses of the effects of LIPS has confirmed the practical benefits of decision and systems sciences - the systematic, quantitative reduction in uncertainty.

To date, the use of LIPS - and, hence, its value - has been restricted to resource allocation within the Tri-Labs' operations budgets. This report extends the role of risk-based prioritization to the support of DOE Total Quality Management (TQM) programs. Furthermore, this paper will argue for the requirement to institutionalize an evolutionary, decision theoretic approach to the policy analysis of the Department of Energy's Program Budget.

The paper is organized into four distinct sections:

- Section 1 develops the background for this paper.

- Section 2 provides a brief description of LIPS and TQM.

- Section 3 defines technical uncertainty, discusses the sources of bias while making decisions under uncertainty, and identifies the rational and ethical basis for integrating risk-based prioritization into TQM.

- Section 4 summarizes the requirement for a quantitative, decision-theoretic approach to policy analysis to enhance current TQM programs. 


\title{
The Role of \\ Risk-Based Prioritization \\ in \\ Total Quality Management
}

\author{
The Integration of \\ Quantitative Policy Analysis \\ and \\ The Management of Uncertainty
}

\author{
C. Thomas Bennett, Ph.D. \\ University of California \\ Lawrence Livermore National Laboratory
}

\section{BACKGROUND}

Decision Theory. The challenges that face government leaders have never been more complex. All stakeholders - the public, industry partners, and Congress are demanding more accountability and responsibility for our nation's resources.

Certainly the rapid increase in our population, with the resulting demands on finite resources, has played an important role in increasing the complexity of decisions. Another important factor is the accelerating change in the technologies with which we surround ourselves. These technologies are more hazardous and have longer time-horizons than ever before.

Yet, as management complexity has increased, scientists from a variety of disciplines have developed a more or less coherent methodology called decision analysis. It is a systems theoretic approach to solving decision problems that was nurtured by scientists in such diverse fields as psychology, economics, management science, and operations research.

Most decision theoretic approaches are relatively sympatric (a concept borrowed from ethology implying that each approach is distinct, yet covers the same ground). The basic components of all decision analysis problems include:
- A perceived need to accomplish some objectives.

- Several alternatives, one of which must be selected.

- The consequences associated with alternatives are different.

- Uncertainty about the consequences of each alternative.

- The possible consequences are not all equally valued. (Keeney, 1982, pg. 807)

The history and scope of decision analysis can be found in several fine articles which describe decision theory (Einhorn and Hogarth, 1981; Keeney, 1982; and, Lopes, 1994).

Risk-B ased Prioritization. Decision theoretic analysts developed the Laboratory Integrated Prioritization System (LIPS) as a policy analysis tool:

"...to integrate and prioritize the spending of DP (Defense Programs) Laboratory resources, while considering the concerns of diverse stakeholders." (Laboratory Integration Prioritization System, Supporting Documentation, 1994, pg. 1-1)

LIPS assists managers in their decisionmaking by formally combining the 
assessments of technical experts with the policy judgments of key stakeholders. As a risk-based prioritization process, LIPS helps managers make rational choices in the midst of technical, economic, and political complexity - and, perhaps most importantly, in the midst of uncertainty.

Organizational effectiveness. During the past half-century, professionals from the field of organizational effectiveness developed a class of methodologies generically called Total Quality Management (TQM). Techniques such as TQM were designed to promote organization efficiency by focusing workers and managers on the feedback loop defined by: (a) customer expectations, (b) customer assessment of the product, and (c) customer satisfaction. See Figure 1.

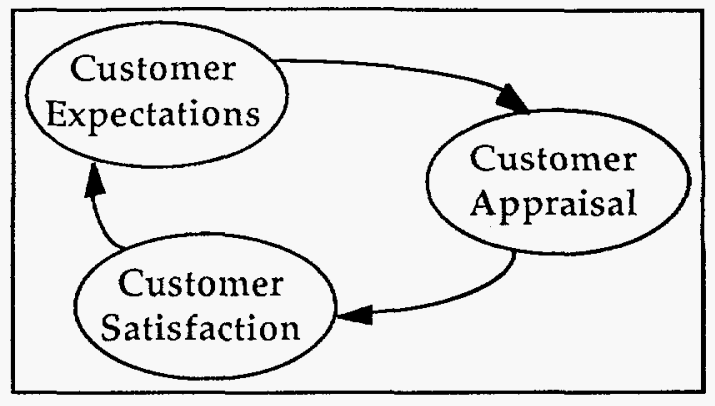

Figure 1. The customer feedback loop which is the essence of Total Quality Management.

However, there is no single TQM process or program (Bennett, 1994). Yet, there is common ground. What most successful TQM programs seem to share mutually is a requirement to measure system processes.

Purpose. Though LIPS and TQM are both systems theorctic in nature, there has been no formal attempt to integrate the two. The purpose of this paper is to examine the theoretical foundations of risk-based prioritization methodologies, like LIPS, in context with modern organizational effectiveness programs, like TQM. 


\section{AN INTRODUCTION TO LIPS \& TQM}

In the following subsections, I will describe LIPS and TQM briefly. These descriptions will provide the context for the main body of the paper - a discussion about the use of quantitative policy analysis in the reduction of managerial uncertainty, and the thorough integration of decision sciences into TQM.

These discussions will be restricted to the Department of Energy (DOE) Defense Programs (DP) oversight responsibilities to the Tri-Lab (Lawrence Livermore, Los Alamos, and Sandia) operations budgets. The term "operations" budget refers to those overhead activities which do not directly participate in bringing funds into the laboratory, but are essential to the success of the laboratory.

\subsection{Description of LIPS}

Because of changing national imperatives, monies allocated to DOE DP have many constraints. In an effort to make DP operations as cost effective as possible, one forward-thinking DP manager initiated a program to ensure logical, equitable, and systematic use of its resources by the National Laboratories, with initial emphasis on the Tri-Labs' operating budgets.

In response to the programmatic requirement to map overhead expenditures onto operating requirements, the Tri-Lab organizations developed a systematic prioritization procedure to help managers make rational, optimal choices about their budgets. The Tri-Lab organizations reported the details of their collaboration in Laboratory Integrated Prioritization System Documentation Support (1994).

Decision analysts intended the principal benefits of LIPS to be the following:

- Integrate requirements and resources

- Communicate the Laboratories needs to mect new or revised requirements
- Identify the relative significance of requirements

- $\quad$ Provide a basis for negotiating requirements and / or funding

- Provide a basis for identifying, determining, and comparing risks

The prioritization model is well documented in the "user's manual" cited above. In brief, LIPS uses a Multiattribute Utility Analysis (MUA) to prioritize the risks and reduce uncertainty.

Multiattribute Utility Analysis (MUA). MUA is a systems analytic and decision theoretic approach that compares alternatives by evaluating the benefits that would accrue in various areas. The following three steps comprise MUA:

- Identification of objectives and evaluation criteria

- Development of measurement scales and value models

- Quantification of decision-maker preferences

For example, you might use MUA to compare cars based on price, reliability, and comfort (the objective and evaluation criteria). See Table 1 for a hypothetical analysis. You would then set up a table with each car as a separate row, with one column allotted to each of the criteria. You would then assign the criteria various dimensions (the measurement scales). Finally, if you value the criteria differently (i.e., price is more important than reliability), you would weight one more than another (the value model), then combine the scores (the quantification of preferences), and make a decision.

LIPS uses criteria such as:

- Public health \& safety

- Worker health \& safety

- Environmental protection

- Safeguards \& security 
The criteria were chosen based on work done by the Nuclear Regulatory Commission for commercial power plants. The value model for the MUA was developed by a Tri-Lab technical working group.

Table 1. An example of a hypothetical Multiattribute Utility Analysis matrix. The criterion score is first, with the rank in parenthesis. If the criteria categories were valued differentially, weighting typically would be applied to the rank scores and combined using a standard multiattribute utility function.

\begin{tabular}{|c|c|c|c|}
\hline Car A & $\begin{array}{c}\$ 10,000 \\
(1)\end{array}$ & $\begin{array}{c}5 \text { garage } \\
\text { days/year } \\
(2)\end{array}$ & $\begin{array}{c}10 \text { chiro- } \\
\text { practic } \\
\text { visits/year } \\
(2)\end{array}$ \\
\hline Car B & $\begin{array}{c}\$ 15,000 \\
(2)\end{array}$ & $\begin{array}{c}2 \text { garage } \\
\text { days/year } \\
(1)\end{array}$ & $\begin{array}{c}20 \text { chiro- } \\
\text { practic } \\
\text { visits/year } \\
(3)\end{array}$ \\
\hline Car B & $\begin{array}{c}\$ 20,000 \\
(3)\end{array}$ & $\begin{array}{c}\text { Comfort } \\
\text { days/year } \\
\text { da) }\end{array}$ & $\begin{array}{c}2 \text { chiro- } \\
\text { practic } \\
\text { visits/year } \\
(1)\end{array}$ \\
\hline
\end{tabular}

Technical experts in various areas of the plant operations (e.g., Technical Information or Budget Division) assign scores. The values are combined by means of a standard multiattribute utility function coded into a simple computer program, and then passed on to the managerial decisionmakers.

Decision Theory and Multiattribute Utility Analysis is well documented in the scientific literature (von Neumann and Morgenstern, 1947; Keeney and Raiffa, 1976; Fischhoff, 1981; Gardenfors and Sahlin, 1988; and, Clemen, 1991). Also, see the Postscript at the end of the paper for current perspectives on MUA.

Summary. LIPS is a systems analytic and a decision theoretic method using multiattribute utility analysis and is designed to reduce technical uncertainty during the policy analysis process. LIPS reduces uncertainty by using a logical and orderly process for prioritizing managerial risks and maximizing utility of organizational goals.

\subsection{Overview of TQM}

The term TQM was coined in 1985 by the Naval Air Systems Command to describe the Command's newly adopted approach to conducting business (Bemowski, 1992). The U.S. Air Force's approach to TQM was based explicitly on Japanese-style management practices. Since then, TQM has come to refer to any set of management practices - developed before or after 1985 - which advocates systems analytic management practices and emphasizes that customer and employee satisfaction, not profits, should be the primary motivation for conducting one's business.

This paper does not go into depth concerning various TQM approaches to business management. There is a special reference section that contains specific citations directing interested readers to some of the primary sources. I have included specific citations concerning the application of TQM to various federal government agencies. See Bennett (1994) for a comparison of selected TQM approaches.

The three essential documents that delineate DOE operating guidelines and TQM implementation procedures are:

- DOE Order 5480.19, Conduct of Operations Requirements for DOE Facilities

- DOE Order 5700.6C, Quality Assurance

- DOE/HR-(1066, Total Quality Management Implementation Guidelines

Of the three documents, DOE/HR-0066 (pg. 3) is the most explicit in terms of identifying key organizational attributes to be assessed. HR-0066 specifically recommends that DOE organizations use the Malcolm Baldrige Award criteria to assess systems and processes. These criteria include (percentages indicate proportion of total quality rating): 
- Customer Focus and Satisfaction (25 percent)

- Quality and Operational Results (18 percent)

- Human Resource Development and Management (17 percent)

- Management of Process Quality (14 percent)

- Leadership (12.5 percent)

- Information and Analysis (7.5 percent)

- Strategic Quality Planning (6 percent)

What is often missed by a cursory study of the Baldrige Award is that its rating categories represent specific, quantifiable operating characteristics of an organization. The National Institute of Standards and Technology (NIST) is the "keeper" of the Baldrige Award and is responsible for establishing the quantitative metrics.

For example, one of the leadership criteria is: "Top executives are directly, visibly, and actively involved in quality related activities (DOE/HR-0066, pg. 65)." To evaluate an organization on this criterion, NIST examiners would directly examine managers' calendars to determine if in fact they had spent time with quality management activities. Other criteria have their own established quantitative measures (Easton, 1993).

DOE does not state specifically that a certain TQM methodology be implemented throughout the agency. However, DOE does strongly urge that contractors and subordinate organizations in the DOE complex abide by the aphorism: "If you can't measure it, you can't manage it." The Baldrige Award endorses the corollary to this maxim: "If you aren't measuring it, you're not managing it."
If subordinate organizations institutionalize the use of DOE/HR-0066 within the DOE complex, then managers will need to incorporate organizational metrics into their normal business operations. Additionally, those same managers will have to ensure that they select contemporary, quantifiable scales standardized by some organization like NIST.

\subsection{Summary}

In the preceding overview section, I have provided a foundation for the integration of risk-based prioritization and TQM.

I characterized LIPS as a logical, orderly approach to the reduction of risk and uncertainty during policy analysis. Risk-based prioritization is rooted in the quantification of expert technical opinion concerning system performance. In the case of LIPS, the process has been limited to reducing risk surrounding the Tri-Labs' operating budgets.

TQM was described as an organizational effectiveness tool that can take on a variety of "looks," depending upon the style of management. However, over the last ten years, TQM has not only become wedded to systems sciences, but has adopted some of the basic principles of operations research. However, to date, decision science techniques, such as riskbased prioritization, have not been integrated explicitly into the application of TQM to budget policy analysis.

In the next section, I will (1) examine how decision science uses risk-based prioritization as an indispensable tool to reduce uncertainty during policy analysis, and (2) evaluate the value of risk-based prioritization as a TQM tool. 


\section{RISK-BASED PRIORITIZATION \& TQM}

To fully appreciate the value of riskbased prioritization and how it might be incorporated into TQM, I believe we need to examine the nature of uncertainty, and how mangers must deal with it as they analyze policy decisions.

\subsection{Technical Uncertainty}

History of uncertainty. Throughout this century, authors have documented the hazards with which we surround ourselves (American Engineering Council, 1928; Pressman, 1928; Herring, 1989; and, Schlager, 1994). These selected compendia capture the failures in our science and technology - from the mundane to the catastrophic.

We assume, of course, that failures in technology were not intentional. Given this, I pose the question: What a priori certainty existed - in the minds of the designers and managers - that technology would not fail us? Surely, developers must have gone about some process to reduce the frequency and consequences of their systems failing.

In many cases, historians and analysts have in fact documented how scientists and policy makers dealt with certainty in technical knowledge. (For reasons of logic, it is uncertainty, rather than certainty, which must be analyzed. Throughout this paper, I will be dealing with uncertainty and failure rather than certainty and success.)

Academicians have written a number of excellent papers and books about technical uncertainty and the role it plays in policy analysis. See, for example, Morgan Henrion, and Morris, 1981; Clark, 1984; Funtowicz, and Ravetz, 1984; Morgan, Morris, Henrion, Amaral, Rish, 1984; Perrow, 1984; Roberts, 1990; Shrivastava, 1992; Sagan, 1993; and, Shrivastava, 1994. Many of the ideas in the following subsections have been synthesized from these authors.

Epistemology of uncertainty. Before examining what role technical uncertainty plays in management sciences and policy analysis, I believe it is important to examine the fundamental nature of uncertainty. It is in the epistemology (the study of knowledge) of uncertainty that we can appreciate the subjective nature of our physical world - as well as the foundation for the quantification of subjective estimates.

As the aphorism goes, "The only certainty is that nothing is certain (Pliny the Elder, c. 23-79 AD)." However, with the modern age of science, we have become particularly arrogant concerning our knowledge about our physical world. We have even come to the belief that there are such truths as physical constants!

Some of the sciences, like physics and chemistry, have developed a list of concepts - the physical constants - which are said to exist in the physical world, independent of our subjective knowledge about them. See Landolt-Börnstein (1992) for the current list of physical constants.

Setting solipsism aside, the fact that physical constants exist may, or may not, be true. For some scientists, it would be a bitter pill to swallow if they had to acknowledge the impermanence of the physical constants:

\footnotetext{
"It would be disheartening to any real scientist to feel that an accepted value of any physical constant would never again be changed. The most characteristic feature of science - in general and particular - is its neverending change. But what one must not overlook is the fact that it is the probable value of any given constant that changes, not its actual value. A belief in any significant variability of the constants of nature is fatal to the spirit of science, as science is now understood." (Birge, 1942, pg. 90. Italics added for emphasis.)
} 
It is clear in this quote from Birge's landmark treatise, that there was something heretical about acknowledging that variability exists in natural physical constants. Yet, in the decade following Birge's paper, one of mathematics' most influential statisticians, Sir Ronald A. Fisher, had another view of the problem:

\begin{abstract}
"The obstacle to which I refer is the existence of variability in the natural world. Only one hundred years ago the inhibitory effect of this obstacle can be seen in many writers; for us today the obstacle does not exist. The familiar concept of a frequency distribution ... comes to our minds, and we recognize that by means of this device,... variability may be accurately specified, and its consequences calculated." (Fisher, 1959, pg. 21)
\end{abstract}

Fisher's view of the physical constants probably represents the other extreme from Birge. And, as may be expected, there is a more moderate view which represents a compromise:

\begin{abstract}
"Strictly speaking, the actual error of a reported value (of a constant) is usually unknowable. Limits to this error, however, can usually be inferred - with some risk." (Eisenhart, 1968, pg. 1201)
\end{abstract}

This quote by a scientist from what is now the National Institute of Standards and Technology represents an aphilosophical position. Whether or not a physical constant exists should not deter us from going about the business of measuring nature - with some risk. The point is that whether or not physical constants exist in nature, uncertainty does exist about their true values because of the subjective nature of all measurements. That is, whether we are measuring the speed of light or the mass of an electron, some private, subjective experience must be exercised in the measurement process.

What role subjectivity played in creating the variability we observe in nature was not always so clear. In 1927, deBray (as reported by Birge, 1942) seriously concluded, based on the historical trend, that $c$, the speed of light, was linearly decelerating at the rate of some four $\mathrm{km} / \mathrm{sec} /$ year. At that rate, the speed of light would be zero in 75,000 years! Just a few years later, in 1934, Edmondson (again, as reported by Birge, 1942) concluded that deBray's calculation was in error by demonstrating that $c$ was not decreasing, but had a damped, sinusoidal period of approximately forty years.

Having roundly criticized deBray and Edmondson, Birge concludes his discussion of $c$ with what was to be a bit of premature confidence:

"Thus, after a long and, at times, hectic history, the value of $c$ has at last settled down into a fairly satisfactory 'steady' state. The same thing can now be said of the other important constants." (Birge, 1942, pg. 101)

A mere nine years later, $c$ had again shifted by more than 2.4 standard deviations of Birge's estimate of uncertainty (Eisenhart, 1968).

It would take almost two more decades before a "solution" to the seemingly ever changing value of $c$ was agreed upon:

"...This new definition (of $c$ ) has the effect of giving a fixed value to the speed of light:

$$
c=299,792,458 \mathrm{~m} / \mathrm{s} \text { exactly, }
$$

...According to this definition, the speed of light can now no longer be measured." (Landolt and Börnstein, 1992, pg. 3-49. Italics added for emphasis.)

What is glossed over is that the meter is measured with respect to how far light travels in one second. (Never mind that the second is measured in terms of how long it takes light to travel one meter.) In other words, the speed of light is defined in terms of the speed of light! Without a doubt, this has to be (to borrow from Islam) the "mother" of all scientific tautologies. Using different technologies, David Pritchard (as reported by Holden, 1994) is taking an analogous approach in defining mass with respect to an "unchanging" standard.

Fortunately, there are some who have tricd to clear the fog brought on by closed logic systems (Norman and Setterficld, 1987). They argue: 
"The behaviour of the atomic constants and the velocity of light, $c$, indicate that atomic phenomena, though constant when measured in atomic time, are subject to variation in dynamical time." (pg. 3)

The two types of cosmic time that Norman and Setterfield refer to are atomic time (based on the period taken for an electron to move around once in its orbit), and dynamical time (based on the period taken for the earth to make one complete orbit of the sun). Furthermore, they believe that the data show that "the two clocks measuring cosmic time are running at different rates" (1987, pg. 3). Briefly, to Norman and Sutterfield, if the Theory of Relativity is to believed, then we must give up our cherished notions of the objective permanence of the physical constants.

The unsettling notion concerning the impermanence of the constants has even been extended to the subjectivity of the fundamental forces of nature. Those who have attempted to take the Theory of Relativity that one final step quantumization of gravity, and its unification with the other forces - have found that the mathematics of space-time may bring us to a Kantian dead end - the subjectiveness of the cosmos.

"Ultimately, the biggest barrier to the construction of a theory of quantum gravity may not be the mathematics, but the interpretation of the mathematics....

"Veteran gravity theorist Chris Isham of Imperial College, London, sees even deeper issues starting to loom - issues long thought to be the preserve of philosophy. Perhaps most central of all is the question of whether space and time are merely constructs of our personal experience, as Immanuel Kant argued some 200 years ago.

'The mere suggestion that such fundamental concepts cannot be relied on in the construction of a theory would fill most physicists with horror. Yet those who dare to tackle the mystery of gravity are learning to live with such possibilities. As Isham puts it: The shadow of Kant is hanging over all of us." (Matthews, 1994, pg. 32)
To conclude this section on the epistemology of uncertainty, and to justify the apparent diversion, I would like to briefly discuss two of what I believe to be the most interesting papers on the role of uncertainty and subjective judgment in the physical and social sciences.

Henrion and Fischhoff (1986). Their paper, entitled "Assessing Uncertainty in Physical Constants," adequately demonstrates that scientists are consistently overconfident in their estimates of the physical constants, including the speed of light, Planck's constant, electron mass, Avogadro's number, as well as several others. Youden (1972), in an earlier and appropriately entitled paper, "Enduring Values," reported a similar phenomenon for the Astronomical Unit. In that paper, Youden showed that each of fifteen estimates, from 1885 to 1961 , were outside the standard deviation of the immediately previous estimate. The overconfidence of the scientists in their own estimates is hardly something that one would expect to occur by chance alone.

What is the basis of this phenomenon? In any estimate of a physical constant, there are two sources of error - the first, called true or random error, is the difference between the measurement and the true or actual value, and is the result of unexplained measurement variability; and the second, called systematic error or bias, is the estimate of the amount of error introduced by specific, but unknown, experimental conditions. Experimenters generate systematic error when they make subjective estimates of their uncertainty about the true error.

Since we cannot know the true value of the physical constants, how are we to separate true error and bias? Müller (1979) contends we should not. I agree.

For example, let us assume we can never know the real value of random error. Furthermore, it is given that we do know the magnitude and direction of systematic error (because it was subjectively estimated by the scientist). Therefore, let us just deal 
with error as if it were systematic or biased only - that is, just make a single, albeit complex, estimate of our uncertainty. Henrion and Fischhoff (1986) and Youden (1972) have already shown that this is probably the case anyway.

Henrion and Fischhoff (1986) argue that while there are apparently limits on what we can do about the magnitude and direction of true error, there are at least some steps we can take in dealing with subjective error, i.e., uncertainty. Henrion and Fischhoff proceed to document carefully the literature describing how people make decisions in the face of uncertainty. (Some of this original literature will be discussed in later subsections.) Henrion and Fischhoff also specifically recommend how scientists can reduce the uncertainty around subjective estimates of the physical constants.

What I will argue in later sections is that the errors, which occur when subjectively estimating the physical constants, also occur when estimating risk or uncertainty associated with policy analysis and management decisions. Importantly, because we have some understanding about what influences our judgment in these settings, we should be able to minimize the magnitude and direction of the error.

Freudenburg (1988). The thesis of Freudenburg's Science paper is that much of the difficulty in risk management occurs as the result of the perception that, on one hand, scientists identify "real," technical risks, and, on the other hand, the public perceives risk within an environment of misinformation and irrationalities.

However, the underlying theme of Freudenburg's paper is that judgments in the face of technical uncertainty, whether made by scientists or the public, will be influenced by known psychological and sociological factors. Furthermore, the factors which influence our estimates of uncertainty can be identified and controlled, at least to some extent.
Summary of technical uncertainty. In this section, I have presented a rather broad review concerning the nature of technical uncertainty in the physical sciences - and, to a lesser degree, the social sciences. I did this so that we may better understand the nature and influence of technical uncertainty during policy analysis.

I pointed out, using the physical constants as an explanatory vehicle, that measurement error (or, uncertainty) may have two sources. True error is the difference between the real value and the randomness introduced by our measurement tools. Bias or systematic error, the portion that always exists, is brought about by the subjective, perceptual, and cognitive nature of every measurement.

Henrion and Fischhoff (1986) and Freudenburg (1988) argued that we all use heuristics when we measure a physical process of nature or the organizational machinations of a group. Furthermore, measurement heuristics follow behavioral rules that have been well documented over the last few decades. Both papers make persuasive arguments that we can limit the magnitude of error and affect the direction of uncertainty, by understanding the unavoidable, subjective nature of those measurements.

In the following sections, I will discuss how the measurement of uncertainty can be the basis for quantitative methods of policy analysis. In doing so, I will review some of the heuristics of judgment.

\subsection{Reduction of Uncertainty}

Objective \& quantitative vs. subjective \& qualitative. During casual conversation, we often lump objective with quantitative and subjective with qualitative. In doing so, we can generate a misleading implication about the precision of our measurements.

The point here is that just because something is objective - a concrete, physical object - it does not restrict us to 
quantitative, numerical measurements. And, conversely, just because something is subjective - a psychologically private, internal concept - it does not restrict us to qualitative, nominal measurement scales.

We can qualitatively measure something that is objective, or quantitatively measure something that is subjective. In both processes, what is important is accuracy (closeness to the true value) and precision (repeatability). As Eisenhart said when he described how to report uncertainty:

"A reported value whose accuracy is entirely unknown is worthless."

(Eisenhart, 1968, pg. 1201)

Whether we are measuring a social and psychological process like policy analysis, or a physical phenomenon like the speed of sound through different media, the accuracy of our measurements is not based on the objectivity nor the subjectivity of the phenomenon. In large part, the accuracy is dependent upon the magnitude of our error or uncertainty.

Control of uncertainty. Conclusions of the classic papers concerning judgment under uncertainty (Kahneman and Tversky, 1972, 1973, and 1974; and, Lichtenstein and Fischhoff, 1977) have, for the most part, gone unchallenged.

There are three major classes of heuristics and biases which influence judgment under uncertainty:

- Representativeness

- Availability

- Adjustment and Anchoring

There are many subclasses of the major influences listed above. I will mention only one or two to provide some insight into how these heuristics and biases influence our judgments.

Representativeness. The representativeness heuristic relies on how closely a sample, $\mathrm{A}$, resembles the population, $B$. The more $A$ resembles $B$, the greater do we believe the probability is that A comes from B. But, there are welldocumented situations when this rule can fail.

Insensitivity to sample size. Consider the following (Kahneman and Tversky, 1974):

"A certain town, is served by two hospitals. In the larger hospital about 45 babies are born each day, and in the smaller hospital about 15 babies are born each day. As you known, about 50 percent of all babies are boys, However, the exact percentage varies from day to day. Sometimes it may be higher than 50 percent, sometimes lower.

For a period of 1 ycar, each hospital recorded the days on which more than 60 percent of the babies born were boys. Which hospital do you think recorded more such days?

- The larger hospital (21)

- The smaller hospital (21)

- About the same (that is, within 5 percent of each other) (53).

The values in parentheses are the number of undergraduate students who chose each answer."

The correct answer is the small hospital. The point here is that people tend to believe that a sampling statistic $(60$ percent) is independent of sample size (small or large number of births). In fact, sampling theory dictates, because of smaller variability of a large sample, that we should expect a 10 percent deviation to have a higher probability in a smaller hospital.

The misconceptions of chance. The misconceptions of chance bias explains that people expect a purely random stochastic process to be represented even in short sequences. Again from Kahneman and Tversky (1974):

\footnotetext{
"In considering tosses of a coin for heads or tails, for example, people regard the sequence $\mathrm{H}-\mathrm{T}-\mathrm{H}-\mathrm{T}-\mathrm{T}-\mathrm{H}$ to be more likely than the scquence H-H-H-T-T-T, which does not appear random."
} 
People apparently tend to believe that a global process should be represented in a sample of that process. This is, of course, the source of the "gambler's fallacy," that chance is a self-correcting process, when, in fact, the chance of any given event becomes more diluted as the process unfolds.

Availability. The availability heuristic refers to the fact that people tend to assess "the probability of an event by the ease with which instances or occurrences can be brought to mind" (Kahneman and Tversky, 1974). The data clearly show that the estimate of the probability of a specific event will be strongly influenced by the number of times an individual has observed that event around them. For example, people's estimates of the occurrence of fire or a specific accident are dependent on how often and recently they have experienced those events.

Adjustment \& Anchoring. The anchoring heuristic refers to the fact that people tend to estimate the value of something depending on the initial starting value. For example, if people are asked to estimate a sample mean, and are given the 90th percentile, their estimate will be higher than the actual value. Conversely, if given the 10 th percentile first, they tend to give an estimate lower than the actual value. If they are given the mean first, and then asked to estimate the 10th and 90th percentiles, the probability distributions will be "tighter" than the actual values. This is true for laymen and experts.

The issue of adjustment and anchoring possesses even more complexity than alluded to in the previous paragraph. In their paper titled "Judged Frequency of Lethal Events," Lichtenstein, et al. (1978) clearly demonstrated that we tend to overestimate low frequency events and underestimate high frequency events.

For risk analysts, this is good news and bad news. If we overestimate low frequency events, we would tend to be more conservative. On the other hand, if we underestimate high frequency events, then we would tend to be less conservative.
Even experts may subject the use of fault trees to what may be an anchoring bias (Fischhoff, Slovic, and Lichtenstein, 1978). They report that experts and laymen alike tend to overestimate the significance of a given fault tree branch, if that branch is decomposed more than others.

Summary. In this subsection, I have detailed some of the fundamental concepts about technical uncertainty. As part of the presentation, I discussed the role of subjectivity in estimating the physical constants. It was shown that uncertainty based on subjective error may be a major contributor to our estimates of such constants as $c$. I wanted to highight the subjective aspects of measurement, and their contribution to uncertainty, so that we may better appreciate the nature of the uncertainty surrounding judgments of probability.

I pointed out that just because we wish to measure a subjective phenomenon quantitatively, it does not mean that we cannot have a great deal of confidence concerning our accuracy or repeatability. However, it is important that we understand what heuristics and biases we bring to the measurement process. The cognitive, perceptual, and social influences on the judgment process can significantly bias the opinions of laymen and experts. The literature concerning technical uncertainty clearly shows that the direction and magnitude of the biases can be controlled.

Having established a groundwork for understanding uncertainty, I will review some of the basic aspects of quantitative policy analysis. In following sections, I will discuss how decision analytic tools, such as risk-based prioritization, can be integrated into TQM.

\subsection{Quantitative Policy Analysis}

Policy analysis. I use the term policy analysis synonymously with such concepts as regulatory and budgetary decisionmaking. That is, policy analysis refers to 
the general process that managers use to shape the course and direction of their organizations or institutions.

In one of the better treatises on quantitative policy analysis, some of the experts in risk analysis highlighted the importance of quantifying uncertainty during decision-making in the following manner :

\begin{abstract}
"Most of the problems which policy analysis must address involves uncertainty...uncertainty about factual matters and physical reality, uncertainty about future events, and uncertainty about peoples' preferences and values. In some way, all policy analysis must deal with this uncertainty. The most common solution is to ignore it, to treat uncertainty parameters and models as if they were known with precision. But another approach, which is seeing increasing application is to try to characterize quantitatively uncertainty in the form of "subjective' or 'judgmental" probability density functions which characterize one or several peoples' beliefs about their current state of understanding." (Morgan, Henrion, and Morris, 1981, pg. 3)
\end{abstract}

I would now like to compare Morgan's, et al. (1981) thought on uncertainty in policy analysis with that of Laplace (1825, as cited by Raiffa, 1970, pg. 274):

\begin{abstract}
"Pierre Simon de Laplace, in $A$ Philosophical Essay on Probabilities, stated that probability is but the 'expression of man's ignorance' and that the probability calculus is relevant to 'the most important questions of life' and not just to repetitive games of chance."
\end{abstract}

As can be seen from Laplace, the issue of uncertainty and decision-analysis has had a long academic history. Even in the years following Morgan's 1981 institutional report, there have been a number of fine open literature papers dealing with quantification of "technical" uncertainty during policy analysis. See, for example, Fischhoff and Whipple, 1981; Winkler and Sarin, 1981; Morgan, Morris, Henrion, Amaral, and Rish, 1984; Lein, 1992; and, Paté-Cornell and Bea, 1992.

None of these papers directly treats the issue of decision analysis techniques (risk- based prioritization) during budgetary analysis. To further highlight this point, I would like to cite a series of articles published in 1994, by the journal Risk Analysis commemorating the tenth anniversary of what has become a landmark risk analysis document (National Research Council, 1983).

Unfortunately, budgetary policy analysis is not dealt with directly by the "Red Book," as it has become known. The National Academy of Science (NAS) does, however, present the consensus paradigm for risk analysis, which has important implications - and, applications - to quantitative budget analysis.

The NAS paradigm divided the risk analysis process into that of "risk assessment," and "risk management." As the authors of the NAS report wrote:

"...judgments made in risk assessment are designated risk assessment policy, that is, policy related to and subservient to the scientific content of the process, in contrast with the policy invoked to guide risk management decisions, which has political, social, and economic determinants." (1983,pg. 37)

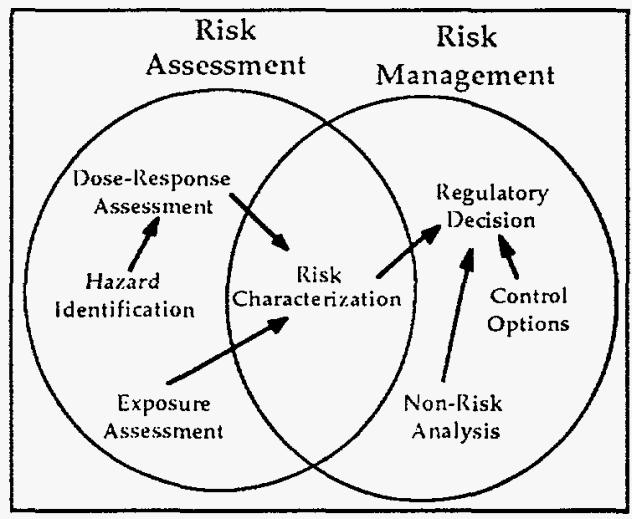

Figure 2. The National Academy of Science's paradigm for risk analysis.

As represented in Figure 2, the process of Risk Assessment (RA) and Risk Management (RM) consists of overlapping activities. In a "tongue-in-check" discussion, Barnes (1994) somewhat indelicately describes RA and RM processes in the following manner: 
- Hazard Identification. Is this stuff toxic?

- Dose-Response Assessment. How toxic is it?

- Exposure Assessment. Who is exposed to this stuff, how long, how often?

- Risk Characterization. So what?

- Risk Management. A response to the public's question: So what are you going to do about it?

In her review of the NAS paradigm, in the process of outlining the risk analysis process, Patton (1994) establishes an important perspective for the users of those management decisions.

"A comparably useful, but often overlooked, use of the paradigm represents the vantage point of the recipient of risk assessment information: the paradigm is also a useful aid for receiving, understanding, and mastering risk science information, and for translating that information for others in the communication chain. In this sense, the paradigm empowers the recipient by offering a diagnostic tool for studying the science used in the risk assessment process or any particular assessment." (Patton, 1994, pg. 375)

As we shall see later, the diagnostic utility of decision analysis, in contrast to the formal output, provides an extremely important tool which can be used for weighing the significance of the analysis.

Given these observations, we might alter the NAS paradigm to suite our own needs concerning the budgetary decisionmaking process. See the following figure.

As represented in Figure 3, budgetary policy analysis, like risk analysis, includes overlapping activities (for example, the process of Budget Assessment (BA) and Budget Management (BM) activitics).

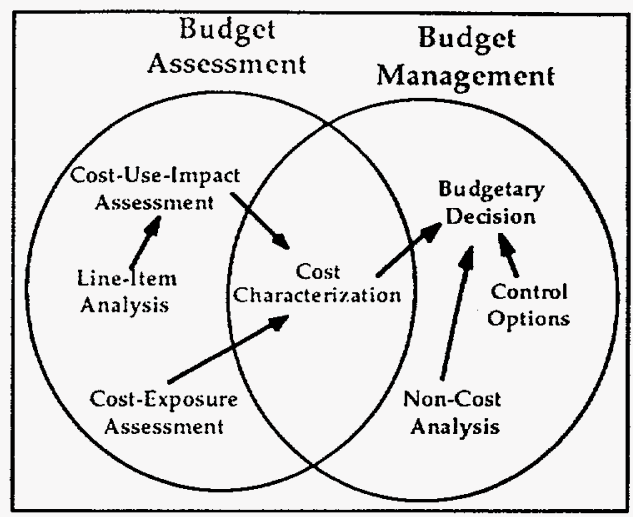

Figure 3. A quantitative budgetary policy analysis model based on the National Academy of Science's risk model.

In a "tongue-in-check" description similar to Barnes (1994), BA and BM activities can be represented as such:

- Line-Item A nalysis. Am I going to have to pay for this?

- Cost-Use-Impact Assessment. How costly is it?

- Cost-Exposure Assessment. Who is going to use this stuff, how long, how often?

- Cost Characterization. So what?

- Cost Management. A response to the public's question: So what are you going to do with our money?

The purpose of this paper is not to elaborate these budgetary activities but to develop a decision theoretic perspective of the budgetary assessment process, which in some sense parallels that developed for risk and uncertainty analysis. Such a perspective will include the concerns of the analysts, the managers, and the customers - in other words, the core of a TQM model.

Ethics and quantification of uncertainty. Barnes (1994) addressed some of the weaknesses of the NAS risk assessment paradigm. It applies equally and explicitly to our model of budgetary uncertainty analysis: 
"A perennial chestnut, the issue of adversity of effect (e.g., Which is worse: cancer or development effects?) has withstood all attempts at definitive resolution by the Agency (the EPA), the NAS, and anyone else for that matter. At bottom, the question of the relative concern to give to leukemia vs. missing limbs, or reproductive effects vs. stratospheric ozone depletion appears to be a value judgment to be made somewhere other than in the RA arena. Although such a statement may be true, it reflects a limitation in the ability of RA to answer the RM question: What are you going to do about these two risks?" (Barnes, 1994, pg. 222)

Clearly, Barne's "adversity of effect" issue has a parallelism in uncertainty during budgetary policy analysis. For example, an overhead budget manager might ask: Should I spend the public's money on protecting my people from the risk of heart attacks or exposure to radiological contamination? These types of questions prompt us to consider the ethical issues of risk-based prioritization and Total Quality Management.

The literature on the social implications of discounting provides a solid platform from which to view the ethical issues of quantitative uncertainty analysis and budget management.

Paté-Cornell (1984) presents a carefully considered discussion of the ethics of discounting. In its simplest form, discounting addresses the following question: What are the future returns on money invested in the present? Again, in the simplest solution to the question, we could apply von Neumann's (1947) axioms of rationality to evaluate discounting's multiattributes.

In evaluating different avenues of discounting, managers must assess (1) the magnitude of their uncertainties, (2) their preferences regarding risks, (3) the minimum rate of return, or (4) those benefits valued most. Paté-Cornell (1984) lists the following questions that managers should consider during discounting:

- Is risk-cost-benefit analysis an appropriate basis for safety decisions and in what cases?
- What is the goal of doing a risk analysis for a given health and safety decision, and what is the meaning of discounting future potential lives (saved or threatened) in risk analysis?

- Is there a fundamental difference between intra- and intergenerational decisions?

- What are the possible definitions of equity (justice, fairness) and what do they imply for decisions affecting the future? (Paté-Cornell, 1984, pg. 19)

While investigating the implications of these questions, Paté-Cornell (1984) points out that, superficially at least, the notion of discounting implies economy of purpose. She writes:

"...the argument often is not whether or not discounting is appropriate ..., but rather whether or not economic efficiency matters in the decision to be made." (Paté-Cornell, 1984, pg. 22)

Paté-Cornell and others raise ethical issues that directly impinge on how workers perceive managers' risk prioritization processes - and, ultimately, on the quality of workers' performance. See the following for additional insights: Keeler, 1982; Kolb and Scheraga, 1990; Moore and Viscusi, 1990; Robinson, 1990; Scheraga, 1990; Cropper, Aydede, Portney, 1991; Shepard, 1992; Broome, 1994.

In this paper, I will not develop fully the ethics of discounting specifically, nor those of other quantitative analytic tools. I will simply state that as risk-based prioritization is developed and integrated into TQM models, managers must carefully consider not just economic efficiency, but also value systems of current and future workers. For, if workers believe that their value systems are not being considered during budgetary policy analysis, then product quality and customer satisfaction surely will suffer. 


\subsection{Conduct of Operations, DOE's TQM Program, \& Budget Analysis}

Review \& overview. To this point in the paper, I have provided a brief description of LIPS and TQM. I have shown how biases in the subjective assessment (quantitative or qualitative) of physical constants or policy analysis can influence estimates of technical uncertainty and judgments of experts. I also have offered a general presentation of some of the ethical implications of quantitative policy analysis.

Decision-Theoretic Tools Described in DOE Documents. In this section, I would like to briefly discuss what DOE's documents currently say about the use of decision-theoretic tools in budgetary policy analysis and management.

DOE Order 5480.19, Conduct of Operations Requirements for $D O E$ Facilities.

The purpose of this Order is:

$$
\begin{aligned}
& \text { "To provide requirements and guidelines } \\
& \text { for Departmental Elements to use in } \\
& \text { developing directives, plans, and /or } \\
& \text { procedures relating to the conduct of } \\
& \text { operations..." (pg. 1) }
\end{aligned}
$$

Despite this statement, paragraph $\mathrm{C}$ (Guidelines), subparagraph 1 (Operations Policies) in Attachment 1 (pg. 1-16) of the Order provides no guidance concerning how a manager is to develop policies. Furthermore, I was unable to find any reference to policy analysis methods and techniques to develop policies for budgetary analysis.

DOE Order 5700.6C, Quality Assurance.

The purpose of this Order is:

$$
\begin{aligned}
& \text { "To establish quality assurance } \\
& \text { requirements for the Department of } \\
& \text { Energy." (pg. 1) }
\end{aligned}
$$

The Order neither defines nor makes reference to methods which should be used to develop policies for budgetary analysis.

\section{DOE/HR-0066, Total Quality Management Implementation Guidelines.}

While the pamphlet urges that DOE departments use strategic planning in the budgeting process (pg. 66), the document does not go on to recommend any specific methodology (e.g., decision theoretic or risk-based prioritization) for budgetary analysis.

\section{National Research Council, Building Consensus: Risk Assessment and Management, The Department of Energy's Environmental Remediation Program.}

The National Academy of Science was chartered by DOE to evaluate and make recommendations regarding environmental risk assessment (National Research Council, 1994). The document provides specific recommendations that state-ofthe-art, quantitative, probabilistic risk assessments be used for identifying the factors in environmental clean-up programs.

Though this document provides specific guidance for quantifying risk, it does not specify any policy analysis nor any management decision-making tools.

Federal Coordinating Council for Science, Risk Assessment: A Survey of Characteristics, Applications, and Methods Used by Federal Agencies for Engineered Systems.

This document was prepared by eight federal agencies, including the Department of Energy and the Nuclear Regulatory Commission. The document states that applications of risk assessment include management support, by providing riskbased perspectives for decision making (pg. 13).

As with the other documents discussed earlier, the Federal Coordinating Council's findings do not develop any decision theoretic tools to aid in management decision making. 
Summary. None of the major DOE "controlling" documents provides any guidance in the use of decision-theoretic tools for management of policies; and, I found no reference to the use of risk-based prioritization for decision-making, in general, or budgetary policy analysis specifically.

\subsection{Integration of TQM, Risk- Based Prioritization, \& Budget Analysis.}

Ethics of capitalism and TQM. It is in the ethics of TQM - as much as its call to analytics - that mandates the use of riskbased prioritization in policy analysis.

The birthright of TQM can be traced to capitalism. Yet, on the surface, the ethics of capitalism are antithetical to the welfare of either the workers or customers.

Capitalism promotes maximizing profits versus costs (which trades stockholders' interests over that of the workers'). Capitalism also attempts to maximize a product's margin (its cost to produce versus its sales price) versus the product's value (worth compared to utility and cost), a trade which favors the stockholders' interests - again over that of customers'.

What TQM brings to the table is that it inextricably ties the profit motive to the interests of workers and customers. TQM promotes a business and management ethic which favors the interests of no single participant of a system. TQM advocates that an organization should measure its own success by how it optimizes (a) the interests of its workers, (b) the value of its product to the customer, and (c) its profits.

The implication of this "TQM Credo" is that we should no longer define success by a unidimensional metric such as profit. TQM would have us define organizational success as a metric with multiple attributes. It follows then, that if we are to measure systematically the success of our organization, we are led to a systems theoretic, decision analytic process such as risk-based prioritization, which uses, as a principal tool, Multiattribute Utility Analysis (MUA).

As I described in carlier sections, MUA is a systematic process by which decisionmakers can list the attributes of various alternatives, weight the importance of the attributes using individual preferences or judgments, and come to an equitable, logical decision.

Summary. In this section, I have closed the argument concerning why a decision analytic tool, such as risk-based prioritization, should be an integral process of TQM.

The ethics model used by TQM has brought about fundamental changes in our perspective of capitalism and, by way of analogy, our perspective of organizational management. The conclusion being that, if during budgetary policy analysis, we were to apply TQM cthics and principles, then we need to systematically consider the interests of all stakeholders - from the public to Congress. One decision theoretic tool that carries empirical consensus in the scientific community is the risk-based prioritization tool called Multiattribute Utility Analysis.

\subsection{Use of Measurement in Managing DOE Policy Analysis}

In a previous section (3.3), I mentioned

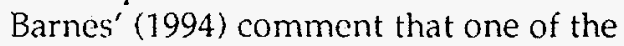
problems of risk-based management process is "adversity of effect." The problem, or more properly, the dilemma, is exemplified by the following question: "Which is worse, lung cancer or breast cancer?"

In a carefully considered response to Cohen's (1985) paper, "Criteria for Technology Acceptability," Otway (1985) weighs risk assessment and risk management: 


\begin{abstract}
"...there is convincing evidence that normal people, completely rational in all generally accepted senses of the word, view technologies in a framework much broader than is possible for risk analysis. In the long run, decision making in a democracy reflects the values of its citizens, and policy decisions about technology must reflect this wider perspective, viewing technology in its larger social context." (pg. 272)
\end{abstract}

I would argue that in policy analysis, decision theoretic approaches take up where risk assessment leaves off. This applies equally well to operations budget analysis or the planning of a research program.

The Department of Energy's Defense Program's Office has much at stake in our post-Cold War era of neo-peace, made up of small, low-intensity, regional conflicts. DP must be responsive to Congressional and Military requirements to ensure our Nation's security by maintaining a safe, nuclear deterrent force. Yet, DP must also be responsive to the international peace initiatives to disarm. These burdens must be considered in light of DP's stewardship of future generations' safety from radiological hazards.

\section{As Otway (1985) wrote:}

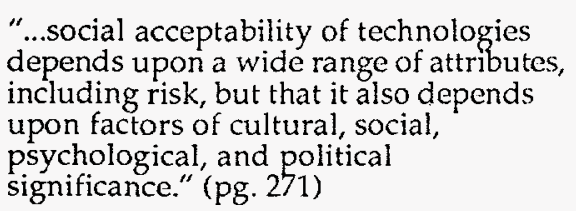

We have here the perfect forum for riskbased prioritization of research and development budgets. If nuclear explosive policy analysis is to address the varied concerns of all national and international stakeholders, decision theoretic methods can logically and equitably provide management guidance.

\subsection{Summary}

In the preceding subsections, I have laid the ground work for understanding technical uncertainty. I examined the role of private, internal psychological processes that enter into making both objective and subjective estimates.

I also developed a budget management model based on the National Academy of Science's risk assessment paradigm. I

highlighted the fact that DOE's "controlling" documents concerning policy analysis do not provide specific guidance concerning budget management.

I followed the subsection on documents with a discussion of the ethics of capitalism and management. I pointed out that if TQM is to address policy analysis issues in an equitable fashion, it must follow a quantitative, systematic approach such as risk-based prioritization.

Section 3, "Risk-Based Prioritization \& TQM," cnded with a brief discussion of the value of applying the ethics of TQM using decision sciences as a backdrop - to the problem of nuclear explosive program policy analysis. 


\section{GENERAL CONCLUSIONS}

In the confines of a limited-scope paper, I have dealt with a wide range of issues, while focusing on the paper's purpose:

Examine the theoretical foundations of risk-based prioritization methodologies, like LIPS, in context with modern

organizational effectiveness programs, like TQM.

The value of risk-based prioritization tools, like Multiattribute Utility Analysis (MUA), is that it can be used to reduce technical uncertainty during policy analysis. The utility of Total Quality Management (TQM) is that it optimizes the expected utility of a system to all the stakeholders - managers and owners, workers, and customers. The question arises: Can an MUA tool, such as the Laboratory Integration Prioritization Tool (LIPS), be integrated fully into TQM methodologies?

Technical uncertainty surrounds all nondeterministic outcomes (which includes most decisions we make). Furthermore, decisions we make in the face of uncertainty are influenced by a number of well known heuristics and biases. The magnitude and direction of the uncertainty, or error, surrounding our decisions may be controlled to some extent, given our understanding of judgment heuristics.

Judgment heuristics modify our technical decisions concerning objective phenomena, like the physical constants, as well as the privately centered, subjective phenomena such as cognitive behavior. The latter becomes particularly important when dealing with policy analysis and management decisions which must incorporate beliefs and values of a variety of stakeholders in a system.

It is in the domain of technical policy analysis - irrespective of whether the policy deals with implementation of high consequence nuclear technology or managing a budget - that decision theoretic tools, such as MUA, can have a positive impact. Over the last decade, the risk analysis community, with those in decision sciences, have clearly identified some of the limits of the risk assessment process.

Risk assessment typically deals with the technical aspects of a management process. For example: "How many fatalities will technology ' $X$ ' produce? Or, will high-consequence technology ' $Y$ ' fail in the next year?" Decision scientists designed Risk Assessment (RA) to assist managers in understanding the consequences of management choices. Risk analysts never intended that RA data be the only data with which a manager made a decision. Somewhere between von Neumann and Morgenstern (1947) and the present generation of managers and analysts, the notion was lost that $R A$ is an analytic tool - not a decision tool.

To make "better" policy choices, managers must turn to decision theoretic methods. (The term "better" is used here in the sense that a manager rationally selects an alternative, which optimizes the values and interests of each system stakeholder.) That managers actually do this may or may not be the case. However, the point is that there are decision theoretic tools for policy management upon which there is much technical consensus.

One such decision tool is the MUA called LIPS. It should be remembered that LIPS was initiated to make Tri-Lab operations budget policy decisions more equitable and responsive to $\mathrm{DOE}^{\prime}$ 's oversight concerns. During the development of LIPS, a new DOE administration began advocating a management philosophy called TQM.

TQM brings to the table an ethics base which necessitates that managers carefully consider the interests of all stakeholders. To this end, LIPS provides a vehicle by which DOE operations managers weigh budget considerations prior to decision making. In this sense, LIPS may be viewed as a tool that supports TQM in general, and budget policy analysis specifically. 
I concluded the main body of the paper with a brief argument that MUA may be useful during DP's' program policy analysis process. MUA could be used to carefully consider the multiple, political influences that DOE DP managers must deal with during annual program budget allocations. 


\section{POSTSCRIPT}

Alternatives to Utility Theory. The term "utility" in MUA makes specific reference to Utility Theory as it was formulated by von Neumann and Morgenstern (1947). In order to develop a set of tractable mathematical solutions, in its basic form, Utility Theory makes a number of simplifying assumptions.

For example, decision makers are assumed to have complete information about the probabilities and consequences of the alternatives. The theory assumes that the decision makers understand the consequences, compute the associated probabilities, and then select the alternative that maximizes the utility function. It does not take much to stretch one's imagination and realize that the actual world does not operate in this manner.

I do not point this out to dismiss Utility Theory. The theory is simple to implement, and in many situations approximates actual outcomés.

However, as a sidebar to my discussion of MUA presented in the main body of the paper, I feel it is important to describe at least one alternative to Utility Theory or, what is probably the most widely accepted alternative, Prospect Theory (PT). I do this not to promote an alternative to LIPS, but merely for completeness of the paper.

Prospect Theory. In the decade following von Neumann and Morgenstern's book, it was clear that Utility Theory did not predict all outcomes of human decision making. In 1956, the economist and Nobel Laureate Herbert Simon hypothesized that people do not optimize, they "satisfice."
What Simon tried to account for were the situations in which people act "irrationally."

The Allais (1953) and the Ellsberg (1961) Paradoxes are typical examples. Briefly, the paradoxes pose probabilistic questions, which force the participants into contradictory behaviors. These conflicting actions demonstrate that people only optimize to a point. Once they believe the solution is "good enough," they stop attempting to reach an optimal solution.

Prospect Theory (Kahneman and Tversky, 1979) handles many of the situations that Utility Theory does not.

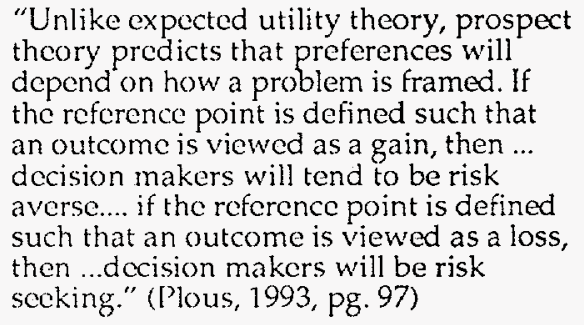

The reader is referred to either the Kahneman and Tversky (1979) paper or to Plous (1993) for a more complete discussion of PT. Again, the intent is not to advocate an alternative to LIP's approach to budget analysis. I felt that it was important for the reader to realize that the literature does recognize the limitations of Utility Theory, and depending upon the setting, Prospect Theory (PT) may prove useful.

Though much recognition is being given to PT, the reader should be aware that because it is much younger, it has not been as thoroughly "exercised" as Utility Theory. As a result, decision analysts have not completely defined PT's limitations. 


\section{REFERENCES}

Allais, P.M. "The Behavior of Rational Man in Risk Situations - A critique of the Axioms and Postulates of the American School," Econometrica, V21: 503-546, 1953.

American Engineering Council, Safety and Production. An Engineering and Statistical Study of the Relationship Between Industrial Safety and Production. New York: Harper, 1928.

Barnes, D.G. "Times are Tough -- Brother, Can You Paradigm?" Risk Analysis, V14, N3:219-223, 1994.

Bemowski, K. "Inside the Baldrige Award Guidelines," Quality Progress, V25, N6:24-28, 1992.

Bennett, C. T. Comparison of Approaches to Total Quality Management, UCRL, in press, 1994.

Birge, R.T. "The General Physical Constants, As of August 1941 with Details on the Velocity of Light Only," Reports on the Progress of Physics, V8:90-134, 1942.

Broome, J. "Discounting the Future," Philosophy and Public Affairs, V23, N2:128-156, 1994.

Burstein, C. "Total Quality Management in Federal Agencies," National Civic Review, V78, N2:103-113, 1989.

Clark, W.C. "Technical Uncertainty in Quantitative Policy Analysis," Risk Analysis, V4, N3:217-218, 1984.

Clemen, R. T. Making Hard Decisions: An Introduction to Decision Analysis Boston: PWS-Kent Publisher, 1991

Cohen, B.L. "Criteria for Technology Acceptability," Risk Analysis, V5, N1:1-3, 1985.

Cropper, M.L., Aydede, S.K., and Porney, P.R. "Discounting Human Lives," American Journal of Agricultural Economics, V73, N5:1410-1415, 1991.

Dorsey, E.A. "Total Quality Management: The Ethical Qualities of T.Q.M." Bulletin of the Science and Technology Society, V13, N2:71-73, 1993.
Easton, G.S. "The 1993 State of U.S. Total Quality Management: A Baldrige Examiner's Perspective," California Management Review, V35, N3:32-54, 1993.

Einhorn, H.J. and Hogarth, R.M. "Behavioral Decision Theory: Processes of Judgment and Choice," Annual Review of Psychology, V32:5388, 1981.

Eisenhart, C. "Expression of the Uncertainties of Final Results," Science, V160:1201-1204, 1968.

Ellsberg, D. "Risk, Ambiguity, and the Savage Axioms," Quarterly Journal of Economics, V75: 643-669, 1961.

Federal Coordinating Council for Science, Risk Assessment: A Survey of Characteristics, Applications, and Methods Used by Federal Agencies for Engineered Systems, Washington, 1992.

Fischhoff, B. Acceptable Risk, Cambridge: Cambridge University Press, 1981.

Fischhoff, B., Slovic, P., and Lichtenstein, S. "Fault Trees: Sensitivity of Estimated Failure Probabilities to Problem Representation," Journal of Experimental Psychology: Human Perception and Performance, V4, N2: 330-344, 1978.

Fischhoff, B. and Whipple, C. "Risk Assessment: Evaluating Error in Subjective Estimates," The Environmental Professional, V3:277291, 1981.

Fisher, R.A. "Mathematical Probability in the Natural Sciences," Technometrics, V1, N1:21-29, 1959.

Freudenburg, W.R. "Perceived Risk, Real Risk: Social Science and the Art of Probabilistic Risk Assessment," Science, V242:44-49, 1988.

Funtowicz, S.O. and Ravetz, J.R. "Uncertainties and Ignorance in Policy Analysis," Risk Analysis, V4, N3:219220, 1984. 
Gardenfors, P. and Sahlin, N. Decisions, Probability, and Utility: Selected Readings, Cambridge: Cambridge University Press, 1988.

Golis, M.J. and Kist, N.C. "ISO 9000, Total Quality Management, and Implications for NDT," Materials Evaluation, V51, N4:462-467, 1993.

Henrion, M. and Fischhoff, B. "Assessing Uncertainty in Physical Constants," American Journal of Physics, V54, N9:791-798, 1986.

Herring, S.D. From the Titanic to the Challenger : an annotated bibliography on technological failures of the twentieth century New York: Garland, 1989.

Holden, C. "Weighing the Atom," Science, V265:1654, 1994.

Kahneman, D. and Tversky, A. "Subjective Probability: A Judgment of Representativeness," Cognitive Psychology, V3:430-454, 1972.

Kahneman, D. and Tversky, A. "On the Psychology of Prediction," Psychological Review, V80, N4:237251, 1973.

Kahneman, D. and Tversky, A. "Judgments Under Uncertainty: Heuristics and Biases," Science, V185:1124-1131, 1974.

Kahneman, D. and Tversky, A. "Prospect Theory: An Analysis of Decision Under Risk," Econometrica, V47: 263-291, 1979.

Keeler, E.B. Discounting of Nonmonetary Effects, U.S. Department of Health and Human Services, report number N-1875HHS, 1982.

Keeney, R.L. "Decision Analysis: An Overview," Operations Research, V30, N5:803-838, 1981.

Keeney, R.L. and Raiffa, H. Decisions with Multiple Objectives: Preferences and Value Tradeoffs, New York:Wilcy, 1976.
Kolb, J.A. and Scheraga, J.D. "Discounting the Benefits and Costs of Environmental Regulations," Journal of Policy Analysis and Management, V9, N3"381-390, 1990.

Kronenberg, P.S. and Loeffler, R.G. "Quality Management Theory: Historical Context and Future Prospect," Journal of Management Science and Policy Analysis, V8, N3: 203-221, 1991.

Landolt, H.H. and Börnstein, R. Numerical Data and Functional Relationships in Science and Technology. New Series. Units and Fundamental Constants in Physics and Chemistry, Ed. in Chief, Madelung, O., Edited by J. Bortfeldt and Kramer, B., Berlin: SpringerVerlag, 1992.

Lein, J.K. "Expressing Environmental Risk Using Fuzzy Variables: A Preliminary Examination," The Environmental Professional, V14:257-267, 1992.

Lewis F.L. Introduction to Total Quality Management in the Federal Government, Washington, D.C.: Office of Personnel Management, Federal Quality Institute, 1991.

Lichtenstein, S., and Fischhoff, B. "Do Those Who Know More Also Know More About How Much They Know?" Organizational Behavior and Human Performance, V20:159-183, 1977.

Lichtenstein, S., Slovic, P. Fischhoff, B., Layman, M., and Combs, B. "Judged Frequency of Lethal Events," lournal of Experimental Psychology: Human Learning and Memory, V4, N6: 551-578, 1978.

Lopes, L.L. "Psychology and Economics: Perspectives on Risk, Cooperation, and The Marketplace," Annual Review of Psychology, V45:197-227, 1994.

Matthews, R. "Can Cravity Take a Quantum Leap?" New Scientist, V143, $N: 28-32,1994$.

Morgan, M.G., Henrion, M., and Morris, S.C. Expert Judgments for Policy Analysis, Brookhaven National Laboratory, BNL 51358, 1981. 
Morgan, M.G., Morris, S.C., Henrion, M., Amaral, D.A.L., and Rish, W.R.

"Technical Uncertainty in Quantitative Policy Analysis - A Sulfur Air Pollution Example," Risk Analysis, V4, N1:201-216, 1984.

Moore, M.J. and Viscusik W.K. “Discounting Environmental Health Risks - New Evidence and Policy Implications," Journal of Environmental Economics and Management, V18, N2: 51-61, 1990.

Müller, J.W. "Some Second Thoughts on Error Statements," Nuclear Instruments and Methods, V163:241-251, 1979.

National Research Council, Risk Assessment in the Federal Government: Managing the Process, Washington: National Academy Press, 1983.

National Research Council, Building Consensus: Risk Assessment and Management, The Department of Energy's Environmental Remediation Program, Washington: National Academy Press, 1994.

Norman, $\mathrm{T}$ and Setterfield, B, The Atomic Constants, Light, and Time, Invited Research Report, Stanford Research Institute International (now SRI), ISBN 0-7258-0363-0, 1987.

Otway, H. "Multidimensional Criteria for Technology Acceptability: A Response to Bernard L. Cohen," Risk Analysis, V5, N4:271-273, 1985.

Paté-Cornell, M.E. "Discounting in Risk Analysis: Capital vs. Human Safety," in Risk, Structural Engineering and Human Error, ed. Grigoriu, M., Waterloo: University of Waterloo Press, 17-32, 1984.

Paté-Cornell, M.E. and Bea, R.G. "Management Errors and System Reliability: A Probabilistic Risk Approach and Application to Offshore Platforms," Risk Analysis, V12, N1:118, 1992.

Patton, D.E. "The NAS Risk Paradigm as a Medium for Communication," Risk Analysis, V14, N3:375-378, 1994.
Perrow, C, Normal Accidents: Living with High-Risk Technologies, New York: Basic Books, 1984.

Plous, S. The Psychology of Judgment and Decision Making, Philadelphia: McGraw-Hill, Inc., 1993.

Pressman, M.B. A Review of the General Literature on Industrial Accidents, Factory Management, Hours of Work, Fatigue and Rest Periods, Lighting, Heating, Ventilation, and Sanitation and Literature on These Subjects in Their Relation to Safety and Production, New York: New York Library of National Bureau of Casualty and Surety Underwriters, 1928.

Raiffa, H. Decision Analysis Introductory Lectures on Choices under Uncertainty, Menlo Park: Addison-Wesley, 1970.

Robinson, J.C. "Philosophical Origins of the Social Rate of Discount in CostBenefit Analysis," Milbank Quarterly, V68, N2:245-265, 1990.

Roberts, K.H. "Some Characteristics of One Type of High Reliability Organization," Organization Science, V1, N2:160-176, 1990.

Sagan S.D. Limits of Safety, Princeton: Princeton University Press, 1993.

Scheraga, [.D. "Perspectives on Government Discounting Policies," Journal of Environmental Economics and Management, V18, N2:65-71, 1990.

Schlager, N. When Technology Fails: Significant Technological Disasters, Accidents, and Failures of the Twentieth Century, Detroit: Gale Research, 1994

Shepard, R.J. "A Critical Analysis of Work-Site Fitness Programs and Their Postulated Economic Benefits," Medicine and Science in Sports and Exercise, V24, N3:354-370, 1992.

Shrivastava, P. "Technological and Organization Roots of Industrial Crises: Lessons from Exxon Valdex and Bhopal," Technological Forecasting and Social Change, V45:237-253, 1994. 
Shrivastava, P. Bhopal: Anatomy of a Crisis, 2nd ed. London: Paul Chapman, 1992.

United States Department of Defense Directive, 5000.51G, Total Quality Management: A Guide for Implementation, 15 February 1989.

United States Department of Energy 5480.19, Conduct of Operations Requirements for DOE Facilities. 9 July 1990, Section I, Part C.

United States Department of Energy DOE/HR-0066, Total Quality Management Implementation Guidelines, December, 1993.

United States Department of Energy Order 5700.6C, Quality Assurance, Attachment 1, Implementation Guide. 21 August 1991.
United States Department of Energy, Laboratory Integration Prioritization System, Supporting Documentation, Relcase Version 2.0, May 5, 1994.

United States Office of Personnel Management, The Federal Quality Institute, Introduction to Total Quality Management in the Federal Government. May 1991.

von Neumann, J. and Morgenstern, $\mathrm{O}$. Theory of Games and Economic Behavior, 2nd ed. Princeton University Press: Princeton, 1947.

Winkler, R.L. and Sarin, R.K. "Risk Assessment: Consulting the Experts," The Environmental Professional, V3:265-276, 1981.

Youden, W.J. "Enduring Values," Technometrics, V14, N1:1-11, 1972. 


\section{REFERENCES-TOTAL QUALITY MANAGEMENT LITERATURE}

Allan F.C. Benchmarking: Practical Aspects for Information Professionals, Special Libraries, V84, N3: 123-130.

Arter, D.R. "Demystifying the ISO 9000/Q90 Series Standards," Quality Progress, V25, N11:65-67, 1992.

Argyris, C. and Schon, D.A. Organizational Learning: A Theory of Action Perspective, Addison-Wesley, 1978.

Balm, G.J. Benchmarking: A Practitioner's Guide for Becoming and Staying Best of the Best, Quality and Productivity Management Association, 1992.

Bemowski, K. "The Quality Glossary," Quality Progress, V25, N2:20-29, 1992.

Bemowski, K. "Inside the Baldrige Award Guidelines," Quality Progress, V25, N6:24-28, 1992.

Bennett, C.T. "Total Quality Management, The Learning Organization, and Benchmarking," A White Paper, University of California, Lawrence Livermore National Laboratory, 1994.

Burstein, C. "Total Quality Management in Federal Agencies," National Civic Review, V78, N2:103-113, 1989.

Camp, R.C. Benchmarking: The Search for Industry Best Practices That Lead to Superior Performance. ASK Press, 1989.

Covey, S.R. Seven Habits of Highly Effective People, New York: Fireside Books, 1989.

Deming, W.E. Out of the Crisis, Cambridge: MIT Center for Advanced Engineering Study, 1986.

Dorsey, E.A. "Total Quality Management: The Ethical Qualities of T.Q.M." Bulletin of the Science and Technology Society, V13, N2:71-73, 1993.

Drucker, P.F. The Future of Industrial Man, Greenwood, 1942.

Drucker, P.F. Concept of the Corporation, Transaction Publishers, 1993.

Drucker, P.F. "The New Productivity Challenge," Harvard Business Review, V69, N6: 69-79, 1991.
Easton, G.S. "The 1993 State of U.S. Total Quality Management: A Baldrige Examiner's Perspective," California Management Review, V35, N3:32-54, 1993.

Franz, L.S. and Foster, S.T. "Utilizing a Knowledge-Based Decision-Support System as Total Quality Management Consultant," International Journal of Production Research, V30, N9:21592171, 1992.

Galagan, P.A. "The Learning Organization Made Plain, Training and Development," V45, N10: 37-44, 1991.

Garvin, D.A. "Building a Learning Organization," Harvard Business Review, V71, N4: 78-91, 1993.

Golis, M.J. and Kist, N.C. "ISO 9000, Total Quality Management, and Implications for NDT," Materials Evaluation, V51, N4:462-467, 1993.

Hayes, R.H. Wheelright, S.C. and Clark, K.B. Dynamic Manufacturing: Creating the Learning Organization. New York: The Free Press, 1988.

Hill, S. "Why Quality Circles Failed but Total Quality Management Might Succeed," British Journal of Industrial Relations, V29, N4:541-568, 1991.

Isaacson, N. and Bamburg, J. "Can Schools Bccome Learning Organizations?" Educational Leadership, V. 50, No. 3, 42-44, 1992.

Kronenberg, P.S. and Loeffler, R.G. "Quality Management Theory: Historical Context and Future Prospect," Journal of Management Science and Policy Analysis, V8, N3: 203-221, 1991.

Lewis F.L. Introduction to Total Quality Management in the Federal Government, Washington, D.C.: Office of Personnel Management, Federal Quality Institute, 1991.

Nonaka, 1. "The Knowledge-Creating Company," Harvard Business Review, V69, N6: 96-104, 1991. 
St. Clair, G. "Benchmarking, Total Quality Management, and The Learning Organization: New Management Paradigms for the Information Environment," Special Libraries, V84, N3: 155-157, 1993.

Schaffer, R.H. and Thomson, H.A. "Successful Change Programs Begin with Results." Harvard Business Review, V70, N1: 78-91, 1992.

Schwartz, G. "What Your Competitors are Reading" Now, Fortune, V129, N1: 110111, 1994.

Senge, P.M. "The Leader's New Work: Building Learning Organizations," Sloan Management Review, V32, N1: 723, 1990.

Senge, P.M. The Fifth Discipline. New York: Doubleday, 1990.

Shields, C.M. "The 5th Discipline- The Art and Practice of the Learning Organization," Educational Administration Quarterly, V28, N4: 555-562, 1992.

Spandolini, M.J. The Benchmarking Book, Amacom, 1992.

Stuart, C. and Drake, M.A. "TQM in Research Libraries," Special Libraries, V84, N3: 131-134, 1993.

Stubrich, G. The Fifth Discipline: The Art and Practice of the Learning Organization, The Columbia Journal of World Business, V28, N2: 108-109, 1993.

Sunday, J.L. and Liberty, L. "Benchmarking the Baldrige Award," Quality

Progress, V25, N9:75-77, 1993.

Swiss, J.E. "Adapting Total Quality Management (TQM) to Government," Public Administration Review, V52, N4:356-362, 1992.

United States Department of Defense Directive, 5000.51G, Total Quality Management: A Guide for Implementation, 15 February 1989.

United States Department of Energy 5480.19, Conduct of Operations Requirements for DOE Facilities. 9 July 1990, Section I, Part C.
United States Department of Energy Order 5700.6C, Quality Assurance, Attachment 1, Implementation Guide. 21 August 1991.

United States Office of Personnel Management, The Federal Quality Institute, Introduction to Total Quality Management in the Federal Government. May 1991.

Walton, M. The Deming Management Method. New York: Putnam Publishing, 1986.

Watkins, D.E. "Human Resource Developer as Leader/Change Agent," Adult Education Quarterly, V41, N4: 251-255.

Watkins, K.E. and Marsick, V.J. Sculpting the Learning Organization. San Francisco: Jossey-Bass, 1993.

Watson, G, The Benchmarking Workbook: Adapting Best Practices for Performance Improvement. Productivity Press, 1992. 